\title{
Delayed speech development, facial asymmetry, strabismus, and transverse ear lobe creases: a new syndrome?
}

\author{
Károly Méhes
}

\begin{abstract}
A 4 year 9 month old boy and his 3 year 5 month old sister presented with delayed speech development, facial asymmetry, strabismus, and transverse ear lobe creases. The same features were found in their mother, but the father had no such anomalies. To our knowledge this familial association has not been described before and may represent an autosomal dominant syndrome.

( $f$ Med Genet 1993;30:76-7)
\end{abstract}

\section{Case report}

The two sibs were referred to our department because of delayed speech development. They were the only children of non-consanguineous Caucasian parents. The father, who was 36 years old, showed no anomalies on physical examination and was of average intelligence. The 30 year old mother was an only child; her parents could not be examined. She only began to speak at the age of 4 years, but later she finished secondary school with satisfactory marks. She was a somewhat anxious person who had been aware of her divergent strabismus and asymmetry of the eyes (figure) since early childhood. She had transverse creases on her right ear lobe, a long, slightly beaked nose, and a high arched palate.

Case 1 , her son, was 4 years 9 months old on admission. After an uneventful pregnancy and delivery with a birth weight of $3200 \mathrm{~g}$ he had
Paediatrics, University Medical

School, József Attila u7, H-7623 Pécs, Hungary.

$\mathrm{K}$ Méhes

Accepted 5 May 1992.

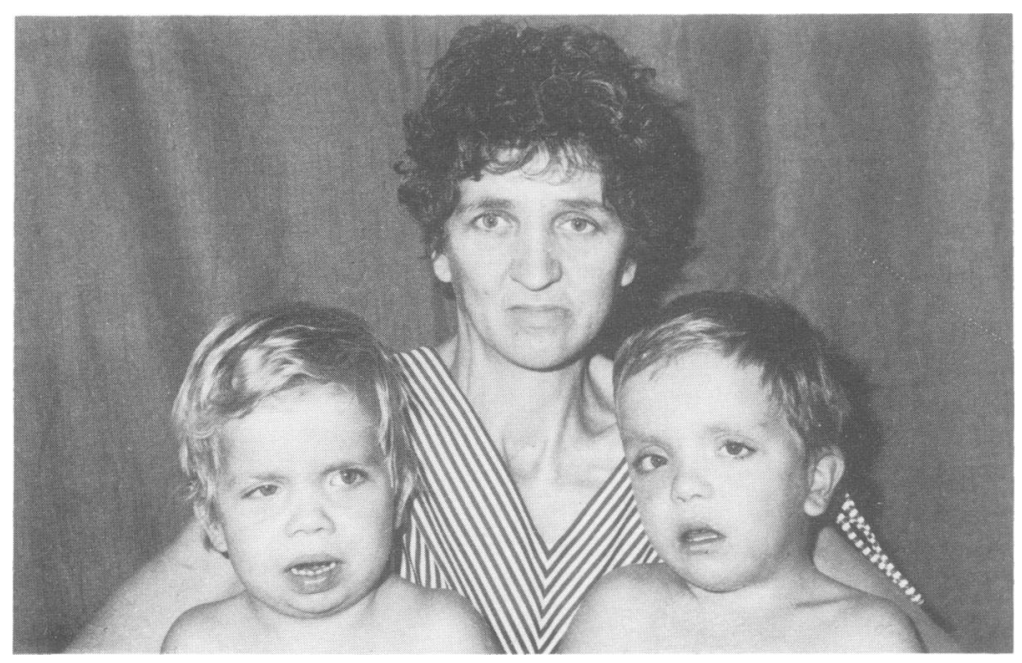

The mother and her affected children. normal psychomotor development. Although his behaviour corresponded to his age, he had only begun to speak a few words. Craniofacial anomalies included convergent strabismus, asymmetrical face, narrow eye opening on the left with normal palpebral fissure length, hypertelorism, low set ears, two ear lobe creases on the left and a pit on the right side, a relatively long philtrum, and a high arched palate.

Case 2, the daughter, was 3 years 5 months old. She was born after an uneventful pregnancy with a birth weight of $3550 \mathrm{~g}$ and her psychomotor development was apparently normal. Understanding appeared normal but instead of speaking she expressed her emotions with gestures. Strabismus and facial hypoplasia on the right side were conspicuous, but these were regarded as harmless familial features that did not bother the parents. She also had hypertelorism, ear lobe creases on both sides, and a high arched palate.

Neurological examination of the mother and her children showed normal closure of the eyes; the function of the cranial nerves was intact and identical on both sides. Radiology showed shortened diameters of the orbits by 1 to $3 \mathrm{~mm}$ and slightly reduced size of the zygomatic bones on the side of the narrow eye opening with a flat face, suggesting congenital hypoplasia in each case.

The most important findings, evaluated according to international ${ }^{1}$ and local $^{2}$ standards, are summarised in the table. Karyotype and biochemistry (including amino acids, urinary glycosaminoglycans, and organic acids) of the patients were normal as were cardiology, abdominal and renal sonography assessments, EEG, audiology, and findings in the velopharyngeal region and the larynx.

\section{Discussion}

To our knowledge the combination of delayed speech development with strabismus, facial asymmetry, and ear lobe creases has not been described so far. The syndrome has some features overlapping other disorders, such as congenital facial asymmetry (McKusick 133900), congenital facial palsy (McKusick 134100), Moebius syndrome (McKusick 157900), Saethre-Chotzen syndrome (McKusick 101400), and Beckwith-Wiedemann syndrome (McKusick $130650),{ }^{3}$ but all these could be ruled out on the basis of the associated anomalies. Similarly, the familial speech delay associated with ptosis, flat nasal bridge, high arched palate, and low set ears described by $\mathrm{Char}^{4}$ does not 
Characteristic features of the mother and her children (centiles in brackets).

\begin{tabular}{|c|c|c|c|}
\hline & Mother & Case 1 & Case 2 \\
\hline Age $(y)$ & 36 & $49 / 12$ & $35 / 12$ \\
\hline Height $(\mathrm{cm})$ & $166(50-75)$ & $110(50-75)$ & $92.5(25)$ \\
\hline Head circumference $(\mathrm{cm})$ & $54(25)$ & $50 \cdot 7(10-25)$ & $51 \cdot 2(50)$ \\
\hline Hypertelorism & - & + & $+1-$ \\
\hline $\begin{array}{l}\text { Interpupillary distance } \\
\text { (calculated } \mathrm{cm} \text { ) }\end{array}$ & $5 \cdot 77(50-75)$ & $5.94(>97)$ & $5.44(97)$ \\
\hline Palpebral fissure length $(\mathrm{cm}) \underset{\mathrm{L}}{\mathbf{R}}$ & $\begin{array}{l}3 \cdot 1(50) \\
3 \cdot 0(25-50)\end{array}$ & $\begin{array}{l}2 \cdot 65(50) \\
2 \cdot 4(25-50)\end{array}$ & $2 \cdot 5(50-75)$ \\
\hline $\begin{array}{l}\text { Strabismus } \\
\text { Narrow eye opening } \\
\text { Facial/bony hypoplasia } \\
\text { Ear length (cm) } R \\
\text { L }\end{array}$ & $\begin{array}{c}+ \\
+L \\
+/-L \\
6 \cdot 4(90) \\
6 \cdot 3(75-90)\end{array}$ & $\begin{array}{l}+ \\
+\mathrm{L} \\
+\mathrm{L} \\
5 \cdot 6(75-90) \\
5 \cdot 8(90-97)\end{array}$ & $\begin{array}{l}+ \\
+R \\
+R \\
5 \cdot 4(75-90) \\
5 \cdot 6(90-97)\end{array}$ \\
\hline Low set ears & - & + & $+1-$ \\
\hline Ear lobe crease (pit) $R$ & + & $(+)$ & + \\
\hline Philtrum length $(\mathrm{cm})^{L}$ & $1 . \overline{4}(25)$ & $\stackrel{+}{\left.1.5^{(75}\right)}$ & $\stackrel{+}{1 \cdot 1}(10-25)$ \\
\hline High arched palate & + & + & + \\
\hline
\end{tabular}

conform to our family because these patients also had a very short philtrum, prominent lips ('duck bill lips'), and widely spaced teeth, while their speech impairment was the result of inability to close the lips.

In conclusion, it seems that our patients exhibit a unique constellation of anomalies which may represent a newly recognised syndrome. Its familiar occurrence is compatible with autosomal dominant or $\mathrm{X}$ linked dominant inheritance.

1 Hall JG, Froster-Iskenius UG, Allanson JE. Handbook of normal physical measurements. Oxford: Oxford University Press, 1989:1-504.

2 Méhes $\mathrm{K}$. Informative morphogenetic variants in the newborn infant. Budapest: Akadémiai Kiadó, 1988:1-229.

3 McKusick VA. Mendelian inheritance in man: catalogs of autosomal dominant, autosomal recessive, and X-linked phenotypes. Baltimore: Johns Hopkins University Press, 1990.

4 Char F. Peculiar facies with short philtrum, duck-bill lips and low-set ears - a new syndrome? Birth Defects 1978;14(6B):303-5. 